\title{
CLINICAL AND LABORATORY EVALUATION OF RESIN BASED AND GLASS IONOMER FISSURE SEALANTS IN PERMANENT MOLARS OF CHILDREN
}

\author{
Shimaa M. Hadwa*, Nahed AA. Abu Hamila**, Talat M. Beltagy*** and Gehan A. El-Oleimy ${ }^{* * * *}$
}

\begin{abstract}
Background: Over the last few decades, several advancements have been made in caries prevention. The use of pit and fissure sealant is one of the essential forms of prevention. Sealants protect the occlusal surfaces, inhibiting bacterial growth and providing a smooth surface.
\end{abstract}

Methods: Clinical study: Forty healthy children aged 6-10 years were selected from the outpatient clinic of the Pedodontic Department, Faculty of Dentistry, Tanta University. 40 molars were sealed with "Ionoseal" \& 40 molars were sealed with "Fissurit F".

Laboratory study: Twenty caries-free human permanent premolars were collected and stored in $0.5 \%$ chloramines solution, then cleaned and stored in distilled water $\left(20^{\circ} \mathrm{C}\right)$ until use. Shear bond strength was measured using a universal testing machine at cross-head speed of $1 \mathrm{~mm} / \mathrm{min}$.

Results: For the clinical study, there was statistically significant difference between the two groups but the quality of restorations gradually decreased from 3-months visit to 9 months visit in both groups. "Fissurit F" had better clinical performance than "Ionoseal". Both materials showed similar results with respect to caries prevention. The bond strength of "Ionseal" was statistically lower than "Fissurit F".

Conclusion: The resin based fissure sealant had better clinical performance than glass ionomer cement. Both materials showed similar results with respect to caries prevention.

KEY WORDS: Fissure sealant, Retention, Caries state and Shear bond strength.

\section{INTRODUCTION}

Dental caries is an infectious, communicable disease resulting in destruction of tooth structure.
This loss of tooth minerals begins on the outer surface of the tooth and can progress through the dentin to the pulp, ultimately compromising the vitality of the tooth ${ }^{(1)}$.

\footnotetext{
*Demonstrator, Pedodontic, Oral Health and Preventive Dentistry Department, Faculty of dentistry,

** Professor of Pedodontics, Faculty of dentistry, Tanta University.

*** Assistant Professor of Pedodontics, Faculty of Dentistry, Tanta University.

**** Lecturer of Dental Biomaterial Department, Faculty of Dentistry, Tanta University.
} 
Occlusal surfaces of posterior teeth are the most vulnerable sites of teeth due to their anatomy favoring plaque retention. ${ }^{(2)}$ About $88 \%$ of the carious lesions in children are located in pits and fissures ${ }^{(3)}$ due to the easy accumulation of bacteria and nutrients in the pits and fissures close of the dentin-enamel junction, and to the difficulty of mechanical cleaning of this area ${ }^{(4)}$. Pits and fissures of permanent molars are vulnerable sites for caries ${ }^{(5)}$.

Prevention is the main objective of modern dentistry, mainly in pediatric dentistry ${ }^{(3)}$. Sealant placement is considered as an effective modality for prevention of caries on occlusal pits and fissures ${ }^{(6)}$.

Sealing pits and fissures is considered a costeffective way of preventing caries development over a great number of years ${ }^{(7)}$. Furthermore the introduction of fluoride-releasing sealants has added another dimension to their role in preventing pit-and-fissure caries ${ }^{(8)}$. Dental sealants were introduced in the 1960s as part of the preventive programs to protect pits and fissures on the occlusal tooth surfaces from dental caries. They prevent the growth of bacteria that promote dental decay ${ }^{(9)}$.

Research advancements in the field of fissure sealants have resulted in an introduction of newer materials that have low micro leakage and penetrate deep into the bottom of the fissures without forming voids and contain fluoride. So, the present study will be conducted to evaluate resin based and glass ionomer composite sealants materials in permanent molars of children.

\section{MATERIALS AND METHODS}

\section{Clinical evaluation}

Study design: This study was randomized clinical trial.

Study setting: Children were selected from the Outpatient Clinic of the Pedodontic Department, Faculty of Dentistry, Tanta University.
Target group: Forty healthy children aged from (6-10) years.

Sample Selection: A split-mouth design was used, in which the fissure sealants were placed in the two first upper or lower permanent molars according to criteria of selection.

\section{Inclusion criteria Bhatia et al ${ }^{\left({ }^{(6)}\right.}$.}

1. Patient cooperation and acceptance of the treatment.

2. The children have bilaterally erupted first permanent molars with deep pits and fissures.

3. Molars free from caries.

\section{Exclusion criteria}

1. Systemic diseases that might interfere with the study.

2. History of abnormal Para functional activity.

\section{MATERIALS AND METHODS}

The clinical situation of the tooth to be sealed was photo documented. All molars were cleaned by explorer to remove any residual plaque or stains found on occlusal surface. The occlusal surfaces of both first permanent molars were flushed with water spray to remove any traces. Local anesthesia if needed and rubber dam were applied.

Group assignment: The molars were divided into two groups as follows

Group I Forty molars were received "Ionoseal" Ionoseal" a light-curing glass ionomer composite cement at right side.

\section{Technique:}

"Ionoseal" was applied on the pits and fissures of occlusal surface according to manufacturer's instructions. The occlusal surface was dried using compressed oil free air then applied the required quantity from the syringe and light cured for 20 seconds.The retention were checked with the help 
of an explorer and ensured that all margins were sealed. Occlusion was checked with the articulating paper.

Group II Forty molars at left side were received "Fissurit F" resin composite fissure sealant.

\section{Technique:}

The occlusal surface was dried using compressed oil free air and etched with phosphoric acid gel $37 \%$ for 30 seconds, rinsed with copious water for 30 seconds. The conditioned areas were dried and the etched enamel noted for a dull frostywhite appearance. The sealant "Fissurit F" was applied with a brush tip applicator according to the manufacturer's instructions. Any air bubbles or voids were removed before curing. Sealant was light cured for 20 seconds. The retention were checked with the help of an explorer and also ensured that all margins were sealed. Occlusion was checked with the articulating paper and adjusted if needed.

\section{Clinical evaluation}

Sealant retention and dental caries status of all tested molars were evaluated at 3,6 and 9 months after sealant application under normal clinical condition with a dental operating light, mouth mirror and sharp dental explorer according to $(\boldsymbol{W} . \boldsymbol{H} . \boldsymbol{O})^{(\mathbf{1 0})}$ and (Boksman and Carson). ${ }^{(1)}$ The retention of the sealant was scored as:

1. Totally present: no crevice detected by explorer

2. Partially lost: partial exposure of fissures

3. Totally lost: complete loss of sealant.

All data were collected, tabulated and statistically analyzed using chi-square test for the clinical part.

\section{Laboratory evaluation}

- Teeth selection

Caries-free human permanent premolars extracted for orthodontic treatment were collected from the Faculty of Dentistry, Tanta University and also from private clinics. Teeth were stored in $0.5 \%$ chloramines solution, then cleaned and stored in distilled water $\left(20^{\circ} \mathrm{C}\right)$ until use $(\boldsymbol{I S O})^{(\mathbf{1 2})}$.

\section{- Specimens preparation}

Total of 20 premolars were embedded in colorless chemically cured acrylic resin. The specimens were ground flat using the usual dental model trimmer. After grinding, flat buccal enamel surface areas of about $3 \mathrm{~mm}^{2}$ were obtained for all the specimens. The specimens were randomly and equally divided into two groups, 10 specimens for each:

Group I "Ionoseal" a light-curing glass ionomer composite cement was applied directly above the ground flat enamel surface after washing and airdrying then cured for 20 seconds.

Group II ( "Fissurit F"), The enamel surface was etched with $37 \%$ phosphoric acid for 30 seconds, followed by a water spray wash for 30 seconds and dried for 15 seconds then cured for 20 seconds.

\section{Bonding procedures}

For each specimen, A Teflon ring with a hole of $3 \mathrm{~mm}$ diameter and height was placed on the enamel surface then gently filled with fissure sealant material \& light cured inside the hole. The Teflon tube and the celluloid strip were gently removed after lightcuring had been completed, and the specimens were stored in distilled water at $37.0 \mathrm{C}$ for $24 \mathrm{~h}$ before shear bond strength measurement. (ISO) ${ }^{(12)}$

\section{Shear bond strength test}

After storage, shear bond strength was measured using a universal testing machine at cross-head speed of $1 \mathrm{~mm} / \mathrm{min}$.

\section{Shear bond strength $(\mathrm{MPa})=$ force $(\mathrm{N}) /$ area $\left(\pi \mathbf{r}^{2}\right)$ $\left(\mathbf{m m}^{2}\right)$}

Data were collected, tabulated and statistically analyzed using Independent sample t-test for the laboratory part. 


\section{RESULTS}

\section{Comparison between gp. I and gp. II regarding} to retention: At 3 months follow up, no significant difference between the two groups. At 6 months, there was statistically significant between "Fissurit F" \& "Ionosal". Which "Fissurit F" showed higher retention than the "Ionosal" ( $\mathrm{p} \leq 0.05)$. At 9 months, the retention rate of "Fissurit F" was significantly higher than the (Group I). There was statistically significant $(\mathrm{p} \leq 0.05)$.

\section{Laboratory study}

The mean Shear Bond Strength, standard deviation values of each of the two groups are presented in Table [3]. It was found that "Ionoseal" had statistically lower shear bond strength than "Fissurit F".

TABLE (1) Comparison between gp. I and gp. II regarding to retention.

\begin{tabular}{|c|c|c|c|c|c|c|c|c|c|}
\hline & \multicolumn{6}{|c|}{ Retention } & \multirow{2}{*}{\multicolumn{2}{|c|}{ Chi-Square }} \\
\hline & & \multicolumn{2}{|c|}{3 months } & \multicolumn{2}{|c|}{6 months } & \multicolumn{2}{|c|}{9 months } & & \\
\hline & & $\mathbf{N}$ & $\%$ & $\mathbf{N}$ & $\%$ & $\mathbf{N}$ & $\%$ & $\mathrm{X}^{2}$ & P-value \\
\hline \multirow{3}{*}{ Ionoseal } & Totally present & 36 & 90.00 & 9 & 22.50 & 0 & 0.00 & \multirow{3}{*}{81.833} & \multirow{3}{*}{$<0.001 *$} \\
\hline & Partially lost & 4 & 10.00 & 23 & 57.50 & 20 & 50.00 & & \\
\hline & Totally lost & 0 & 0.00 & 8 & 20.00 & 20 & 50.00 & & \\
\hline \multirow{3}{*}{ Fissurit F } & Totally present & 39 & 97.50 & 29 & 72.50 & 9 & 22.50 & \multirow{3}{*}{51.182} & \multirow{3}{*}{$<0.001^{*}$} \\
\hline & Partially lost & 1 & 2.50 & 11 & 27.50 & 30 & 75.00 & & \\
\hline & Totally lost & 0 & 0.00 & 0 & 0.00 & 1 & 2.50 & & \\
\hline \multirow{2}{*}{ Chi-square } & $X^{2}$ & \multicolumn{2}{|c|}{2.047} & \multicolumn{2}{|c|}{26.494} & \multicolumn{2}{|c|}{35.562} & & \\
\hline & P-value & \multicolumn{2}{|c|}{0.152} & \multicolumn{2}{|c|}{$<0.001 *$} & \multicolumn{2}{|c|}{$<0.001 *$} & & \\
\hline
\end{tabular}

\section{Comparison between gp.I and gp.II regarding to carious statue:}

At 6 months: No significant difference between the two groups.

At 9 months: caries state between two groups was statistically insignificant.

TABLE (2) Comparison between gp. I and gp. II regarding to carious statue.

\begin{tabular}{|c|c|c|c|c|c|c|c|}
\hline & \multicolumn{4}{|c|}{ Caries } & \multirow{2}{*}{\multicolumn{2}{|c|}{ Chi-Square }} \\
\hline & & \multicolumn{2}{|c|}{6 months } & \multicolumn{2}{|c|}{9 months } & & \\
\hline & & $\mathbf{N}$ & $\%$ & $\mathbf{N}$ & $\%$ & $X^{2}$ & P-value \\
\hline \multirow{2}{*}{ Ionoseal } & Carious & 1 & 2.50 & 4 & 10.00 & \multirow{2}{*}{0.853} & \multirow{2}{*}{0.355} \\
\hline & Sound & 39 & 97.50 & 36 & 90.00 & & \\
\hline \multirow{2}{*}{ Fissurit F } & Carious & 0 & 0 & 3 & 7.5 & \multirow{2}{*}{1.385} & \multirow{2}{*}{0.239} \\
\hline & Sound & 40 & 100 & 37 & 92.5 & & \\
\hline \multirow{2}{*}{ Chi-Square } & $\mathbf{X}^{2}$ & \multicolumn{2}{|c|}{1.399} & \multicolumn{2}{|c|}{0.157} & & \\
\hline & P-value & \multicolumn{2}{|c|}{0.237} & \multicolumn{2}{|c|}{0.692} & & \\
\hline
\end{tabular}

TABLE (3) Comparison between" Fissurit F" \& "Ionoseal" mean shear bond strength and standard deviation

\begin{tabular}{|c|ccc|ccc|c|c|}
\hline \multirow{2}{*}{ Groups } & \multicolumn{4}{|c|}{ Shear Bond Strength (MPa) } & \multicolumn{2}{c|}{ T-Test } \\
\cline { 2 - 7 } & \multicolumn{3}{|c|}{ Range } & Mean & \pm & SD & T & P-value \\
\hline Ionoseal & 1.053 & - & 4.716 & 2.928 & \pm & 1.180 & \multirow{2}{*}{-4.701} & $<0.001 *$ \\
\hline Fissurit F & 4.231 & - & 12.733 & 7.747 & \pm & 3.020 & & \\
\hline
\end{tabular}




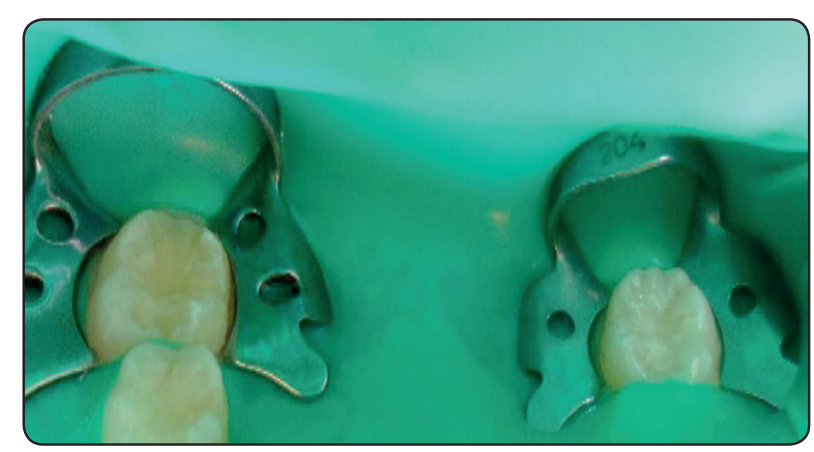

Fig. (1) At 3 months evaluation, no sealant loss from "Ionoseal" at right side and from "Fissurit" $\mathrm{F}$ at left side and also no caries.

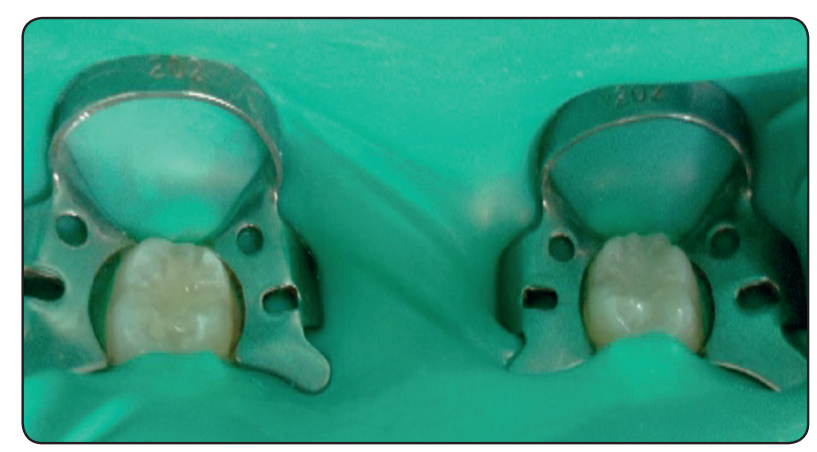

Fig. (2) At 6 months, no sealant loss for both molars also no caries.

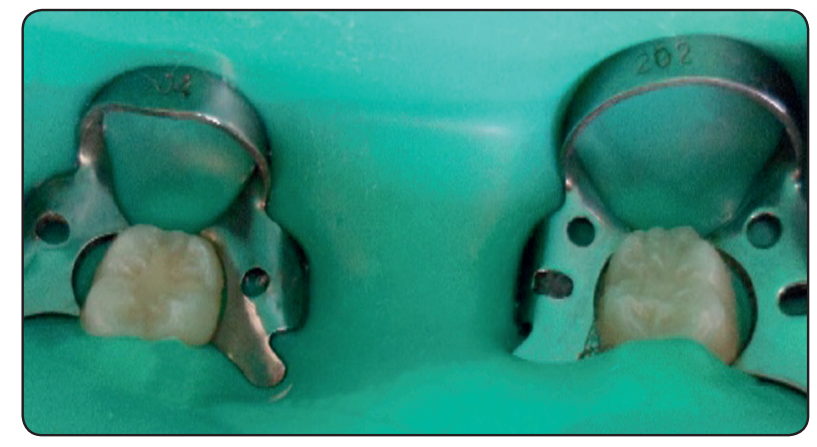

Fig. (3) At 9 months evaluation, both molars showed partial sealant loss.

\section{DISCUSSION}

The present study was being directed to clinical evaluation of glass-ionomer composite cement (Ionoseal) as a fissure sealant in first permanent molars compared with the resin composite (Fissurit F). Also, the shear bond strengths of both sealants to enamel were evaluated.
Regarding the sample of the present study, 40 healthy children aged from 6-10 years were selected for the clinical study. The age of children was selected 6 and over where the first permanent molars become well erupted. This was in agreement with Bargale and Raju, ${ }^{(13)}$; Ninawe et al., ${ }^{(14)}$ whose sample was at the same age but disagreed with, Ulusu, et al. ${ }^{(15)}$; Guler and Yilmaz, ${ }^{(16)}$ who had selected older children.

The selection criteria for the presence of bilaterally well erupted first permanent molars with deep pits and fissures and the split mouth design was chosen, let the sealing on both first permanent molars to be exposed to an identical environment, thus, eliminating any bias. These agreed with Bargale and Raju, ${ }^{(13)}$; Bhatia et al. ${ }^{(6)}$ that used the same criteria.

The procedures had been achieved by using a rubber dam; these agreed with Bargale and Raju ${ }^{(13)}$; Innes $^{(17)}$; kumaran $^{(18)}$ but disagreed withJafarzadeh

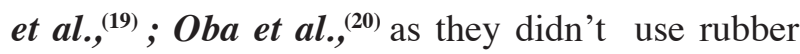
dam but used cotton rolls for moisture controls. The use of rubber dam may be a contributory factor to the high success rate of the sealant placement in this study, not only for maintaining a dry field of operation, but also for its contribution to behavior management of the children.

The retention rate is a major point of concern when a study tests the clinical performance of a FS material ${ }^{(21)}$. In this study when comparing the clinical performance of the two materials, at 3 month recall visits, there were no statistical difference between the two groups regarding to retention. In contrary, at 6 and 9 month, there was statistically significant difference between the two groups ( $\mathrm{p} \leq$ $0.05)$. There is poor retention of glass ionomer composite cement (Ionoseal) when compared with resin based sealant (Fissurit F).

These results agreed with Forss and Halme, ${ }^{(22)}$; Poulsen et al., ${ }^{(32)}$; Skrinjaric etal. ${ }^{(24)}$;Subramaniam et al. ${ }^{(25)}$; Bargale and Raju, ${ }^{(13)}$; Baseggio et al., ${ }^{(26)}$; 
Prashanth et al. ${ }^{(27)}$ as they concluded that the glassionomer sealant had poorer retention than the resinbased sealant. Also this result in agreement with Yýlmaz et al., (28) as they observed that the retention of "Fissurit F" was higher than compomer based sealant at 12 and 24 months follow up examination. In addition, Ninawe et al., ${ }^{(14)}$; Oba et al. ${ }^{(20)}$ they reported that "Fissurit F" showed better retention than 2 flowable composite resin material used as fissure sealant.

Also These results in accordance with Ulusu, et al., ${ }^{(15)}$; kumaran $^{(18)}$; Liu et al. ${ }^{(29)}$ who reported that the retention of fluoride-releasing resin sealant was better than that of the ART sealant, over 24 months.

The lower retention rate obtained with the GIC when compared with the resin based sealants may be due to improper adhesion of the GIC cement to the enamel surface (no etching), brittle nature, lower compressive and tensile strengths of the glass ionomer sealant and a lower abrasion resistance ${ }^{(30)}$ Also may be due to lack of toughness, early water sensitivity which may affect in retention rate of GIC. ${ }^{(31,32)}$

In spite of poor retention of GIC, it is used as fissure sealants due to their chemical bond to enamel without previous etching (simple in technique and saving time) which helps to decrease the child's anxiety and continuous fluoride ion release $(14,16,33)$.

These results disagreed with Antonson et al. ${ }^{(33)}$ as they observed that resin-based (Delton) and (GC Fuji Triage White) exhibited similar retention rates at 24 months. They explained that by using of a bond surface conditioner with the glass ionomer sealant. Lower retention rates obtained with resinbased sealants in their research might be the result of inadequate moisture control.

The results of the present study revealed that no significant difference between the two materials in caries prevention at all recall visits. The "Fissurit $\mathrm{F}^{\prime}$ showed only three molars had caries and in "Ionoseal" four molars had caries at 9 months.
These results in agreement with Poulsen et al. ${ }^{(23)}$; Beiruti et al. ${ }^{(34)}$; Yengopal et al. ${ }^{(35) ;}$ Niederman. ${ }^{(36)}$; Prashanth et al. ${ }^{(27)}$; Yýlmaz et al. ${ }^{(28)}$; Seth, ${ }^{(37)}$; Antonson, et al. ${ }^{(33)}$; Ulusu, et al. ${ }^{(15)}$; Liu et al ${ }^{(29)}$. They reported that there is no significant difference between the use of GIC and resin-based fissure sealants on permanent teeth in the prevention of dental caries.

There is no evidence that either material was superior to the other in the prevention of dental caries. Therefore, both materials appeared to be equally suitable for clinical application as fissure sealant materials. Yengopal et al. ${ }^{(35)}$.

A relevant factor that should be considered when glass ionomer material is being used as a sealant material is that even after it has been clinically lost, small amount of sealant will be left at the bottom of the fissures and continue to release fluoride. So, in spite of its partial loss, protection is still afforded to the tooth structure, and fluoride plays a pivotal role in enamel remineralization ${ }^{(38)}$.

\section{Shear bond strength test}

An in-vitro part of the present study was performed aiming to correlate the clinical research with the basic understanding of the science. Bond strength test was selected as indicator for the shear bond strength. Shear bond strength measures the ability of sealant to bond to tooth structure. Bond strength is more predictive of materials retentive potential, hence about its durability and utility ${ }^{(39)}$.

It was a statistically significant difference in bond strengths among two groups as "Fissurit F" had high bond strength than "Ionoseal". This Agreed with the result of Bishara et al. ${ }^{(40)}$ they reported that resin based provided the strongest shear bond strength. The glass ionomer provided significantly lower bond strength. Also agreed with the result Sfondrini, et al. ${ }^{(41)}$ concluded that the bond strength of the composite resin was significantly higher than that of the resin-modified glass ionomer in all the 
groups tested $(P<.0001)$. Also in the same line of the result Papacchini et al. ${ }^{(42)}$ concluded that the conventional and the resin-modified glass ionomers measured bond strengths significantly lower than those of any resin-based materials. Moreover in accordance with the result Bekes et $\boldsymbol{a l} .{ }^{(43)}$ as they concluded that "Fissurit F" had higher bond strength than smart seal. Also this result agreed with Pushpalatha et al. ${ }^{(44)}$ who concluded that the unfilled resin sealant (Clinpro) showed a better shear bond strength than filled fissure sealant.

The main advantages of GIC are its ability to adhere to untreated enamel surfaces as it bond to enamel surface by chemical bond ${ }^{(45)}$. But in the study of Khodadadi et al. ${ }^{(46)}$ founded that "Ionoseal" without etching and bonding application had significantly greater microleakage than the other groups $(\mathrm{p}<0.001)$, while there was statistical no significant difference between the microleakage of Ionoseal and the other groups (Fissurit FX Fuji II light cured, Grandio flow), after etching and bonding application $(\mathrm{p}>0.05)$

\section{CONCLUSION}

Based on the results of the present study, it was concluded that:

1. "Fissurit F" had better clinical performance than Ionoseal .

2. Both materials showed similar results with respect to caries prevention.

3. The bond strength of "Ionseal" was statistically lower than "Fissurit F".

\section{REFERENCE}

1. National Institutes of health Consensus Development Panel. Diagnosis and Management of Dental Caries throughout Life. The J Am Dent Assoc. 2001; 132:1153-1161.

2. Brown LJ, Selwitz RH. The impact of recent changes in the epidemiology of dental caries on guidelines for the use of dental sealants. J Public Health Dent .1995; 55:274-91.
3. Grande RH, Pedroso de Lima AC, Rodrigues-Filho LE, Witzel MF. Clinical evaluation of an adhesive used as a fissure sealant. Am J Dent.2000; 13:167-70.

4. Tandon S, Kumari R, Udupa S. The effect of etch-time on the bond strength of a sealant and on the etch-pattern in primary and permanent enamel: an evaluation. ASDC J Dent Child .1989; 56:186-90.

5. Carvalho JC, Ekstrand KR, Thylstrup A: Dental plaque and caries on occlusal surfaces of first permanent molars in relation to stage of eruption. J Dent Res 1989, 68(5):773-779.

6. Bhatia M R, Patel A R, Shirol D D. Evaluation of two resin based fissure sealants: A comparative clinical study. J Indian Soc Pedod Prev Dent. 2012 ;30:227-30.

7. Dennison JB, Straffon LH, Smith RC. Effectiveness of sealant treatment over five years in an insured population. J Am Dent Assoc. 2000; 131: 597-605.

8. Ripa LW. Dental materials related to prevention-fluoride incorporation into dental materials: reaction paper. Adv Dent Res. 1991; 5:56-59.

9. Splieth CH, Ekstrand KR, Alkilzy M, Clarkson J, Meyer-Lueckel H, Martignon S, et al.,. Sealants in dentistry: outcomes of the ORCA Saturday Afternoon Symposium 2007. Caries Res. 2010; $44: 3-13$.

10. World Health organization. WHO Basic oral health survey, $4^{\text {th }}$ edition; Geneva1997.

11. Boksman L, carson B .Two year retention and caries rate of ultraseal xt and fluoroshield light -cured pit and fissure sealant. Gendent $1998 ; 46: 184-187$.

12. ISO/TS 11405. Dental material-- Testing of adhesion to tooth structure 2003.

13. Bargale S, Raju O S. The Retention Of Glass Ionomer And Light Cure Resin Pit And Fissure Sealant Using Replica Technique - An Invivo Study. J of Dent Scien. 2009 ; 9 :

14. Ninawe N, Ullal NA and Khandelwal V .A 1-year clinical evaluation of fissure sealants on permanent first molars . Contemp Clin Dent. 2012; 3: 54-59.

15. Ulusu T, Odabaş ME, Tüzüner T, Baygin O, Sillelioğlu H, Deveci C, Gökdoğan FG, Altuntaş A. The success rates of glass ionomer cement and a resin-based fissure sealant placed by fifth-year undergraduate dental students. Eur Arch Paediatr Dent.2012; 13:94-7.

16. Guler C, Yilmaz Y.A two-year clinical evaluation of glass ionomer and ormocer based fissure sealants. J Clin Pediatr Dent. $2013 ; 37(3): 263-7$. 
17. Innes N. Rubber dam use less stressful for children and dentists. Evid Based Dent. 2012; 13(2):48.

18. Kumaran P. Clinical evaluation of the retention of different pit and fissure sealants: a 1-year study. Int J Clin Pediatr Dent. 2013; 6(3):183-7.

19. Jafarzadeh M, Malekafzali B, Tadayon N, and Fallahi S. Retention of a Flowable Composite Resin in Comparison to a Conventional Resin-Based Sealant: One-year Followup J Dent. 2010; 7 (1): 1-5.

20. Oba AA; Sönmez I S ; Ercan E ; Dülgergil T .Comparison of Retention Rates of Fissure Sealants Using Two flowable Restorative Materials and a Conventional Resin Sealant: Two-Year Follow- Med princ practi 2012;21:234-237.

21. Lygidakis NA, Oulis KI. A comparsion of Fluoroshield with Delton[R] fissure sealant:Four year results. Pediatr Dent 1999; 2(7): 429-431.

22. Forss H, Halme E. Retention of a glass ionomer cement and a resin-based fissure sealant and effect on carious outcome after 7 years. Community Dent Oral Epidemiol 1998; 26: 21-25.

23. Poulsen S, Beiruti N, Sadat N . A comparison of retention and the effect on caries of fissure sealing with a glassionomer and a resin-based sealant. Community Dent Oral Epidemiol . 2001;29(4):298-301

24. Skrinjaric K, Vranic DN, Glavina D ,Skrinjaric I. Heattreated glass ionomer cement fissure sealants: retention after 1 year follow-up. Int J Paediatr Dent 2008; 18: 368-373.

25. Subramaniam P, Konde S, Mandanna DK. Retention of a resin-based sealant and a glass ionomer used as a fissure sealant: a comparative clinical study. J Indian Soc Pedod Prev Dent. 2008 ; 26(3):114-20.

26. Baseggio W, Naufel FS, Davidoff DC, Nahsan FP, Flury $\mathrm{S}$, Rodrigues JA. Caries-preventive efficacy and retention of aresin-modified glass ionomer cement and a resin-based fissure sealant: a 3-year split-mouth randomised clinical trial. Oral Heal Prev Dent. 2010; 8(3):261-8.

27. Prashanth V.K, Nagesh L,Anil V. Ankola , Pradnya Hegde, Shushma Nayak. Comparison of glass -ionomer (FujiIII) and resin based fissure sealants (3M ESPE) one year clinical year clinical trial. JPDA 2010; 19(1): 024 -0 29.

28. Yýlmaz Y, . Beldüz N, Eyübo O. A two-year evaluation of four different fissure sealants. Europe Archiv Paediatric Den .2010;11: 88-92
29. Liu B Y, Xiao Y, Chu C H, and Man Lo E C. Glass ionomer ART sealant and fluoride-releasing resin sealant in fissure caries prevention - results from a randomized clinical trial BMC Oral Health. 2014; 14: 54.

30. Ashwin R, Arathi R. Comparative evaluation of microleakage between Fuji VII glass ionomer cement and light cured unfilled resin: A combined in vivo in vitro study. $\mathrm{J}$ Indian Soc Pedod Prev Dent. 2007; 25(2):86-87.

31. Chestnutt IG, Schafer F, Jacobson AP, Stephen KW. The prevalence and effectiveness of fissure sealants in Scottish adolescents. Br Dent J. 1994;177:125-9.

32. Kargul, B.; Tanboga, I.; Gulman, N.A. comparative study of fissure sealants Helioseal Clear Chroma[R] and Delton[R] [FS.sup.+]: 3 year results. Europ Archiv Paediatric Den. 2009; 10(4):218-222.

33. Antonson SA, Antonson DE, Brener S, Crutchfield J, Larumbe J, Michaud C, Yazici AR, Hardigan PC, Alempour S, Evans D, Ocanto R. Twenty-four month clinical evaluation of fissure sealants on partially erupted permanent first molars: glass ionomer versus resin-based sealant. Am Dent Assoc. 2012; 143 (2):115-22.

34. Beiruti, N., Frencken, J. E., Van't Hof, M. A. and Van Palenstein Helderman, W. H. Caries-preventive effect of resin-based and glass ionomer sealants over time: a systematic review. Community Dentistr and Oral Epidemio .2006, 34: 403-409.

35. Yengopal V, Mickenautsch S, Bezerra A C. and Leal S C. Caries-preventive effect of glass ionomer and resin-basedfissure sealants on permanent teeth: a meta analysis. J Oral Science. 2009, 51:373-382,

36. Niederman R . Glass ionomer and resin-based fissure sealants are equally effective? Evidence-Based Dentistr Acade J. $2010 ; 11: 10$.

37. Seth S. Glass ionomer cement and resin-based fissure sealants are equally effective in caries prevention. J Am Den Assoc . 2011; 142 :5 551-552.

38. Pereira AC, Pardi V, Mialhe FL, Meneghim Mde C, Ambrosano GM. A 3-year clinical evaluation of glass-ionomer cements used as fissure sealants. Am J Dent. 2003; 16(1):23-27.

39. Olio G .Bond strength testing-What does it mean? Int Dent J 1993;43:492-498. 
40. Bishara S E, . Gordan V V, , VonWald L, . Jakobsen J R. Shear bond strength of composite, glass ionomer, and acidic primer adhesive systems.Am J Orthodontics and Dento facial Orthopedics. 1999; $115: 24-28$.

41. Sfondrini MF, Cacciafesta V, Pistorio A, Sfondrini G . Effects of conventional and high-intensity light-curing on enamel shear bond strength of composite resin and resinmodified glass-ionomer .Am J Orthodontics and Dentofacial Orthopedics. $2001 ; 119,(1): 30-35$.

42. Papacchini F, Goracci C, Sadek F T, Monticelli F, Garcia-Godoy F, Ferrari M . Microtensile bond strength to ground enamel by glass-ionomers, resin-modified glassionomers, and resin composites used as pit and fissure sealants. J Dent.2005; 33 (6):459-67.
43. Bekes K, Riediger S, Schaller HG, Gernhardt C R .Bond Strength of Sealants on Saliva Contaminated and Demineralized Enamel . Int Poster J Dent Oral Med. 2011, 13 (1) 514.

44. Pushpalatha HM, Ravichandra KS, Srikanth K, Divya G, Done V, Krishna KB, Patil V .Comparative evaluation of Shear bond strength of different Pit and fissure Sealants in Primary and Permanent teeth - An In-Vitro Study. J Int Oral Health.2014; 6:84-9.

45. Mejare I, Mjor IA. Glass ionomer and resin-based fissure sealants: a clinical study. Scand J Dent Res. 1990; 98: 345-350.

46. Khodadadi E, Esmaeili B, Karimian N, Khafri S. Evaluation of microleakage of Ionoseal filling material as a fissure sealant agent. J Dent Res .2014; 3 : 39 - 45. 